16. Колесникова И.А. О критериях гуманизации образования // Гуманизация образования. Теория. Практика. СПб, 1994. С. 37-45.

17. Крылова Н.Б. Культурология образования. М.: Народное образование, 2000. 272 с.

18. Киященко Л.П. Что сознание понимает в знании? // Что значит знать?: сборник научных статей. М.: Центр гуманитарных исследований, 1999. С. 100110.

19. Краевский В.В. Методология педагогического исследования. Самара: СГПИ, 1994. 165 с.

20. Асмолов А.Г. Культурно-историческая психология и конструирование миров. М: МПСИ; Воронеж: НПО «МОДЭК», 1996. 768 с.
21. Брожик В. Марксистская теория оценки / пер. со словац. М.: Прогресс, 1982. 264 с.

22. Бездухов В.П. Гуманизация образования в изменяющемся мире // Кулюткин Ю.Н., Бездухов В.П. Ценностные ориентиры и когнитивные структуры в деятельности учителя. Самара: СГПУ, 2002. С. 22-65.

23. Каган М.С. Философская теория ценности. СПб.: ТОО ТК «Петрополис», 1997. 205 с.

24. Дробницкий О.Г. Мир оживших предметов. М.: Политиздат, 1967. $351 \mathrm{c.}$

25. Бездухов В.П. Культура и образование // Кулюткин Ю.Н., Бездухов В.П. Ценностные ориентиры и когнитивные структуры в деятельности учителя. Самара: СГПУ, 2002. С. 66-173.

\title{
MORAL EDUCATION OF STUDENTS IN THE CULTURAL AND EDUCATIONAL SPACE OF THE HIGH SCHOOL
}

(C) 2016

S.V. Pupkov, doctor of pedagogical sciences, associate professor, professor of Sociology Department Ryazan State University named after S.A. Yesenin, Ryazan (Russia)

Abstract. The necessity of the moral education of students of high school students as an initiation to the values of which are in the teacher-written cultural and educational space. Amended scientific understanding of the concept of «educational space» and proved that the substantive content of the notion of «cultural and educational space » gets through the involvement of the term «culture». The essence of cultural and educational space of the university lies in its multi-dimensionality, which is expressed in infinity broadcast through the channels of education and training culture as the experience of, the experience of spiritual and practical development of the world in the moral experience moral, value relationships according to the criterion limit it (experience) of the base (value of a person), by which the subjectobject, object-subject and subject-subject relations are optional. The content of the cultural and educational space, formed the subject-object and subject-subject relationship, the relationship between them becomes dialectical by the object-subject relationship in which there are values that are axiological nucleus of activity, axiological form of culture. Determine the purpose of the subject-object and subject-subject relations as the content of the image of cultural and educational space, and on the basis of this mission revealed features of pedagogical activity of the teacher conducting the moral education of students: to provide storage, reproduction, broadcast culture as the experience of concluded (experience) in ostensive, imperative, axiological forms of culture, its forms-principles; organization of the work of students with cultural forms; student organization ascent from axiological forms of culture its forms-principles; transfer of experience of spiritual and practical development of morality in the world, the experience of behavior and activity, experience, moral, value relations.

Keywords: student; teacher; school; education; moral education; space; cultural and educational space; value; attitude; the subject-object relations; object-subject relations; subject-subject relationship; essence; content; function.

УДК 378

\section{ВЛИЯНИЕ СРЕДСТВ ИНОСТРАННОГО ЯЗЫКА НА ДИНАМИКУ ПРОФЕССИОНАЛЬНЫХ МОТИВОВ СТУДЕНТОВ}

(C) 2016

Т.И. Руднева, доктор педагогических наук, профессор, заведующий кафедрой теории и методики профессионального образования

А.Б. Храмцова, кандидат педагогических наук, доцент кафедры иностранных языков и профессиональной коммуникации Самарский наџиональный исследовательский университет имени академика С.П. Королёва, Самара (Россия)

Аннотащия. На основе проведенного мониторинга жизненных планов выпускников школ города Самары доказывается актуальность проблемы выбора вуза и профессии с целью приобретения профессиональных компетенций. В меняющихся условиях жизнедеятельности общества студентам необходимо приобрести регулятивные механизмы для успешного взаимодействия с представителями профессионального сообщества на международном уровне, что требует сформированности профессиональных мотивов. Результатами анкетирования студентов перового и второго курса доказывается, что совокупность образовательных средств при изучении иностранного языка способствует активизации не только познавательной деятельности студентов, но и усилению потребности в приобретении профессиональных компетенций, позволяющих интегрироваться в профессиональное сообщество. Таким образом, иностранный язык становится средством развития профессиональной мотивации и механизмом становления языковой личности, успешно социализирующейся в международном профессиональном пространстве. Методический аспект проблемы представляется условиями овладения ино- 
странным языком: вербально-семантическим, тезаурусным, прагматическим. Сравнительный анализ результатов экспериментальной работы подтверждает целесообразность формирования готовности студентов к интеграции в новый тип социальной реальности в ходе коммуникативного образования. Доказывается, что результат коммуникативного образования достигается интеграцией двух моделей (модели языковой личности и модели профессиональной деятельности), чему способствуют средства иностранного языка.

Ключевые слова: профессиональный выбор; жизненные планы выпускников; профессиональные мотивы; языковая личность; средства социализации; удовлетворенность обучением; коммуникативная компетентность; профессионально-ориентированный иностранный язык; профессиональная подготовка; модель деятельности; модель языковой личности; профессиональное самосознание.

В условиях фатальных перемен в обществе актуальной социальной проблемой является выбор вуза и профессии абитуриентами, а также приобретение профессиональных компетенций. На смену одних моделей выбора вуза [1, с. 33] приходят другие: так, модель «проб и ошибок» (влияние семьи, друзей, протест и др.) и модель «самостоятельного выбора» (положительный образ представителя профессии в жизни и литературе, оценка своих возможностей) заменяются моделью «гарантированного поступления» (соответствие баллов ЕГЭ заданному вузом порогу проходимости). Мониторинг жизненных планов выпускников школ города Самара (интервьюирование абитуриентов - выборка 256 человек - 2015 год) показал, что значительно снижается число поступающих, стимулом для которых при поступлении в вуз является уже не престижность профессии (назвали престижным выбираемый факультет $60,2 \%$ абитуриентов), а желание получить высшее образование, диплом $-54,7 \%$. Выбор вуза и профессии по интеллектуальным мотивам составил 30\%. Стремление стать профессионалами обнаружило $47,6 \%$ поступающих в вуз, а получить глубокие специальные знания - 26,1\%. Таким образом, начиная с первого курса усложняется процесс профессиональной подготовки студентов, сопровождаемый низким волевым мотивом (проявляют его $44,9 \%$ опрошенных), невысокой организованностью, отсутствием стремления осваивать профессиональные ценности. Неразвитость механизма рефлексии актуализирует задачу развития личностных и профессиональных компетенций.

В динамично меняющихся условиях жизнедеятельности необходимы регулятивные механизмы, которые будут уравновешивать организм во внешней среде за счет усвоения ценностей среды и интеграции в нее. Следует учитывать тот факт, что для свободной ориентации в поликультурном мире, для взаимодействия с представителями профессионального сообщества на международном уровне необходимо владеть иностранным языком на уровне коммуникативной компетентности [2]. Чисто нормативный язык специальной дисциплины не создает основу для интеграции в международное профессиональное пространство. Таким образом, задачи профессиональной подготовки студентов в вузе дополняются задачей обучения жизни в поликультурном обществе, обучения общению как средству социализации. Среда вуза обуславливает стиль жизни и общения, формируя коммуникативную компетентность студента [3, с. 150-155]. Вместе с тем, сугубо нормативный язык специальных дисциплин не дает почвы для профессиональной самореализации на международном уровне. Необходимы другие языковые средства, расширяющие возможности для восприятия и понимания процессов окружающего мира и профессиональной сферы. Иностранный язык как учебная дисциплина имеет большой потенциал для формирования языковой личности, обладающей многослойным и многокомпонентным набором языковых средств для осуществления речевых поступков разной степени сложности.

Иностранный язык является значимым фактором становления профессионала, его коммуникативной компетентности. Доказано, что языковая личность обладает способностями для полноценного участия в межкультурной коммуникации. И это становится целью обучения студентов иностранному языку. О готовности к деловому общению с коллегами другой языковой картины мира свидетельствуют уровни овладения иностранным языком. На первом уровне, вербально-семантическом, происходит освоение языковой картины мира для понимания окружающей действительности. На втором уровне, тезаурусном, приобретается сумма знаний о картине мира (своеобразие картины мира определяется тем, что происходит опредмечивание индивидуального, группового и этнического вербального и невербального опыта). Понимание текста или фразы через свой тезаурус требует определенных мыслительных операций, мотивации на овладение иностранным языком для профессиональных целей. Таким образом, становится важным, чтобы студент осознавал себя вторичной языковой личностью, испытывающей потребность к саморазвитию для индивидуального стиля иноязычного общения. Третий - мотивационный (прагматический) уровень является высшим, свидетельствующим о совокупности способностей к восприятию и переработке речевых текстов, которые различаются степенью структурно-языковой сложности, глубиной отражения иноязычной действительности, определенной целевой направленностью.

Анкетирование студентов первого курса (выборку составили 152 человека, поступивших на первый курс в Самарский университет, 2015 год) показало, что при изучении иностранного языка профессиональные мотивы обнаруживают $25 \%$ студентов, а когнитивные 43,7\%. Вместе с тем, удовлетворенность обучением иностранному языку составил 0,59 , а в целом обучением в вузе $-0,65$. Индекс лежит в пределах от +1 до - 1 [4, с. 200-210]. Таким образом, иностранный язык может быть не только средством формирования языковой личности, но и средством, меняющим характер мотивации при выборе вуза и профессии (удовлетворенность обучением в выбранном вузе и обучением иностранному языку дают значимую корреляцию, $\mathrm{r}=0,765)$. Доказательством роли иностранного языка для сдвига мотива на цель (профессиональная ориентация) являются следующие полученные результаты по материалам анкетирования первокурсников: низкая направленность на изучение иностранного языка в неязыковом вузе (индекс интереса к изучению ино- 
странного языка составил 0,420 ; удовлетворенность результатами изучения иностранного языка составила 0,333; индекс самооценки способностей к освоению иностранного языка составил 0,250. В итоге обнаружена недостаточная учебная мотивация, неосознанность первокурсниками необходимости коммуникативной компетентности для профессиональной деятельности [5, с. 50-55]. Одновременно низкий показатель самооценки способностей к освоению иностранного языка $(\mathrm{J}=0,250)$ свидетельствует о языковых трудностях и эмоциональном неблагополучии, что значительно снижает познавательный интерес и потребность в получении профессиональных знаний.

В ходе пилотного исследования предпринималась попытка определить, насколько развиты основы для формирования первокурсников как языковых личностей. Обнаружено, что лингвокоммуникативная компетентность характерна для 52,6\% первокурсников; лингводидактическая компетентность - для 25,7\%; лингвострановедческая - для 60,3\%. Поскольку лингвокоммуникативная компетентность обеспечивает семантический уровень развития языковой личности, обучение иностранному языку для профессиональных целей должно направляться на формирование коммуникативных и рефлексивных способностей. Когнитивный уровень развития языковой личности средствами иностранного языка должен обеспечивать развитие аналитических способностей; прагматический уровень - развитие проектировочных способностей.

На основании полученных результатов пришли к следующим выводам:

1) организация профессиональной подготовки студентов первого курса требует учета их жизненных планов, обнаруженных при выборе вуза и профессии;

2) средством развития профессиональной мотивации является иностранный язык, обучение которому должно осуществляться в контексте профессиональной и жизненной ситуации;

3) готовность студентов к интеграции в новый тип социокультурной реальности обеспечивается коммуникативным образованием, результат которого представляется языковой личностью, интегрирующей лингвокоммуникативную, лингводидактическую, лингвострановедческую компетенции.

Могут ли быть другие результаты, если определены и апробированы отобранные средства учебного процесса с установкой на развитие учебно-познавательной активности студентов первого курса? Возможна ли динамика показателей (мотивация на получение высшего образования, направленность, удовлетворенность учебным процессом, в частности, обучением иностранному языку) становления языковой личности?

Сравнительный анализ результатов, полученных при опросе студентов второго курса (лонгитюд) - 122 человек, 2015 год (математики, физики, химики, юристы) показал следующее: профессиональные мотивы обнаруживают 59\% опрошенных (на 35\% увеличилось число таких студентов); удовлетворенность характером обучения составила 0,79 (было 0,65); удовлетворенность обучением иностранному языку составила также 0,79 (было 0,59). Таким образом, совокупность средств, активизирующих познавательную деятельность студентов, значительно меняет характер мотивации. Дополнительные опросные материалы подтвердили, что обучение иностранному языку для профессиональных целей, как процесс освоения профессиональной роли, влияет на мотивацию выбора вуза и профессии, стимулируя процесс социальных ожиданий, удовлетворение которых связано с содержанием профессиональной сферы. Усиливается потребность в изучении иностранного языка, что обусловлено положительными эмоциями, которые свидетельствуют о приближении удовлетворения потребности, активизируя ассоциативное мышление, способствуя непроизвольному запоминанию, снижая речевые зажимы, ускоряя реакцию на восприятие языкового материала и облегчая речевые ситуации. В итоге увеличивается индекс самооценки способностей к освоению иностранного языка $(\mathrm{J}=0,612$, было 0,250$)$. $\mathrm{C}$ ростом интереса к изучению иностранного языка $(\mathrm{J}=0,666$, было 0,42$)$ повышается удовлетворенность результатами освоения иностранного языка специальности $(\mathrm{J}=0,54$ было 0,333$)$ - данный результат связан с величиной потребности в освоении иностранного языка как средства профессиональной самореализации.

Для студентов второго курса характерны значительные изменения в структуре коммуникативной компетентности, формирование которой способствует становлению студента как языковой личности. Так, на $30,2 \%$ больше студентов второго курса демонстрируют лингвокоммуникативную компетенцию (было $52,6 \%$, стало 82,8\%); лингводидактическую компетенцию - на 27,4\% (было 25,7\%, стало 53,1\%). Значительно меняется показатель уровня развития языковой личности студентов второго курса: величина когнитивного ядра в структуре языковой личности увеличилась на 42,6\% (было 42,4\%, стало 85\%); величина прагматического ядра выросла на $38 \%$ (было 42\%, стало $80 \%$; величина семантического ядра возросла на 43,5\% (было 44\%, стало 87,5\%). В итоге было подтверждено, что показатели когнитивного ядра языковой личности дают динамику за счет взаимодетерменированности лингводидактической компетенции и аналитических способностей, формирование которых обеспечивается отбором языкового материала на основе полевого подхода; показатели прагматического ядра языковой личности дают динамику за счет взаимодетерменированности лингвострановедческой компетенции и проектировочных способностей, что достигается применением страноведческого материала при обучении студентов иностранному языку; показатели семантического ядра языковой личности дают динамику за счет взаимодетерменированности лингвокоммуникативной компетенции и коммуникативных способностей, формированию которых способствуют активнее методы освоения иноязычной информации [6].

Придерживаемся точки зрения, что формирование вторичной языковой личности происходит под влиянием первичной языковой личности, сформированной родным языком: типы понимания картины мира на родном языке детерминируют готовность языковой личности к общению на иностранном языке, пробуждая рефлексию своего речевого опыта. Эти процессы усиливаются мотивацией к изучению иноязычной культуры. Лингвострановедческий материал обогаща- 
ет содержание обучения иностранному языку, поскольку его объектом становится культура носителей чужого языка. Содержание страноведческих текстов вызывает потребность в самостоятельном изучении иностранного языка, что свидетельствует о силе мотивации к речевому общению [7, с. 310-315]. Страноведение, отражающее нравы и обычаи народа, имеет большое значение для понимания социальной действительности, что в итоге превращает изучение языка в удовольствие (эстетическая мотивация), инициирующее его активное изучение. Внутренняя мотивация, являясь побудительной силой, определяет отношение личности к овладению иностранным языком. Ее разновидностью является коммуникативная мотивация - потребность говорить на иностранном языке либо потребность к расширению кругозора с профессиональной целью. Для преподавателя иностранного языка процесс развития коммуникативной мотивации студентов является сложным, так как овладение им происходит в атмосфере родной речи, где иностранный язык является искусственным средством общения. Сохранению коммуникативной активности студентов способствуют виды занятий, их содержание, методы и формы работы [8]. Таким образом, актуализируется проблема деятельности преподавателя иностранного языка, создающего атмосферу партнерского общения.

Сравнительный анализ результатов исследования показал, что резервы для влияния на мотивацию и профессиональные планы студентов следует находить в содержании учебного процесса и средствах его организации.

Проблема средств обучения профессионально ориентированному языку приобретает особую значимость, поскольку юридический речевой акт имеет четкую стратегию. Логика и доказательность, смысловая законченность требуют развитого аналитического мышления. Речевой акт должен быть аргументированным, обоснованным. Психологами доказана тесная связь мышления с процессами общения [9, c. 180-188], что послужило основанием для лингвистических исследований, обусловленных результатами изучения мышления. Речь, как форма осуществления мышления [10, с. 80-88], позволяет в профессиональной педагогике использовать понятие «языковое мышление», механизмами которого являются абстракция, обобщение, трансформация, синтез, комбинирование. Мотивы мыслительной деятельности дают возможность проследить взаимозависимость речи и мышления [11, с. 152-156]. Процесс порождения речи требует постоянного решения интеллектуально-логических задач, обеспеченных абстрактным мышлением, имеющим словесную поддержку на всех этапах анализа. В итоге язык является средством самовыражения.

Интегральный критерий качества профессионального образования выражается профессиональным, инновационным, саморазвивающимся критериями. Результат профессиональной подготовки выражается личностными качествами, которые обеспечивают успешность решения профессиональных задач. Относительно двух интегрирующихся моделей (модель деятельности и модель языковой личности) следует выделять их доминанты: если для языковой личности это коммуникативная компетентность; то для профессионала (в частности, юриста) - это профессиональ- ное самосознание, под которым понимаем осознание себя как субъекта в пространстве правоохранительной деятельности, в системах профессионального общения и собственной личности $[12$, с. 58-88]. Задачный подход к отбору содержания учебных дисциплин позволяет организовать имитационное обучение, интегрирующее специальные ситуативные задачи (модель деятельности) и коммуникативные задачи (модель языковой личности). Специальные задачи (задачаоценка профессиональной ситуации, задача-разбор документации, задача-упражнение) поддерживаются коммуникативно-ориентированными, обладающими многофункциональностью (коммуникативные операции в виде социальных действий, выполняемых в ходе деловой и ролевой игры)

Таким образом, средствами формирования коммуникативной компетентности становятся: учебный предмет - иностранный язык; основной вид деятельности по освоению иностранного языка - коммуникативная деятельность в виде диалогового общения; инструмент общения - профессиональные ситуации, активизирующие становление совокупности лингвистических компетенций. Обучение, погружающее в процесс общения, вырабатывает стиль поведения, профессиональный почерк будущего юриста, ответственного за результаты принимаемых решений, влияющих на судьбу другого человека. В итоге гармония личного и социального достигается языковыми средствами, так как речь составляет аспект общественной деятельности человека и не может быть отделима от мышления и процессов общения. Качество обучения студентов иностранному языку, как средство формирования мысли, обусловлено мотивацией, в частности, профессиональными мотивами, в числе которых мотивы приобретения компетенций, позволяющих интегрироваться в международное пространство.

\section{СПИСОК ЛИТЕРАТУРЫ:}

1. Студент и образовательное пространство: мотивация и социально-профессиональные ориентации / Н.Ю. Волова и др. Самара: Изд-во «Самарский университет», 2001. $180 \mathrm{c}$.

2. Приданова М.В., Сорокопудова Ю.А. Технология межкультурной педагогической интеграции в условиях неязыкового вуза, // Известия Самарского научного центра РАН, 2009. Т. 11. № 4 (6). С. 14341436.

3. Бондарева С.К.Психолого-педагогические проблемы интегрирования образовательного пространства. М.: Изд-во Московского психолого-социального института; Воронеж: Изд-во НПО «МОДЕК», 2005. $352 \mathrm{c}$.

4. Ядов В.А. Социологическое исследование: методология, программы, методы. Самара: Издательство «Самарский университет», 1995. 328 с.

5. Руднева Т.И., Храмцова А.Б., Храмцов Е.Б. Формирование профессиональной компетентности студентов - будущих юристов. Самара: Издательство «Самарский университет», 2011. 148 с.

6. Храмцова А.Б. Обучение студентов в контексте профессиональной и жизненной ситуации // Образование в современном мире: сборник научных трудов всероссийской научно-практической конференции. Самара: Изд-во «Самарский университет», 2012. C. $186-188$. 
7. Маслоу А.Х. Мотивация и личность. СПб.: Питер, 2007. $352 \mathrm{c}$

8. Руднева Т.И. Средства формирования коммуникативной компетентности студентов // Известия Самар. науч. центра Рос. акад. наук, 2012. Т. 14. № 2-3. C. $634-638$.

9. Лурия А.Р. Речь и мышление. М.: Академия, 1973. $298 \mathrm{c}$.

\section{INFLUENCE OF DYNAMICS OF STUDENTS PROFESSIONAL MOTIVES BY MEANS OF A FOREIGN LANGUAGE}

(C) 2016

T.I. Rudneva, doctor of pedagogical sciences, professor, head of Theory and Methods of Professional Education Department

A.B. Khramtsova, candidate of pedagogical sciences, associate professor of Modern Languages and Professional Communication Department Samara National Research University, Samara (Russia)

Abstract. On the basis of Samara high school graduates life projects monitoring an issue urgency of high education institution choice and profession for the purpose of acquisition of professional competences is proved. In dynamic environment of societal life students need to acquire regulatory means for successful interaction with professional community representatives internationally that demands professional reasons formedness. Educational and informative activity of students is the most important means of students' quality training improvement. In recent years researchers even more turn to study of training outcome which depends on the applied pedagogical means. Interest in studying of vocational training result from such subjective characteristic as motivation of high education receiving is unreasonably underestimated. Results of this research reflect new tendencies of modern high education: the integration processes setting new productive characteristics of vocational education quality - aspiration for career development, interest to creation of personal development trajectory. First and second year students survey results prove that set of educational means when studying foreign languages promotes revitalizing not only student cognitive activity but also reinforcement of professional competences acquisition requirement allowing to implode into professional association. As a result the foreign language becomes an evolvement means of professional motivation and the mechanism of linguistic identity formation that is successfully socialized in international professional area. The methodical aspect of a problem is presented by conditions of a foreign language acquisition: verbal and semantic, thesaurus, pragmatical. The comparative analysis of experimental work results confirms the expediency of students' readiness formation for integration into new type of social reality in the course of communicative education. It is proved that the result of communicative education is achieved by integration of two models (the model of the linguistic identity and model of professional activity) that is assisted by means of a foreign language.

Keywords: professional adoption; high school graduates life projects; professional reasons; linguistic identity; socialization means; education satisfaction; communicative competence; professionally oriented foreign language; professional development; model of activity; model of linguistic identity; professional self-consciousness.

УДК 378

\section{СПЕЦИФИКА ДЕЯТЕЛЬНОСТИ СПЕЦИАЛИСТОВ УЧЕБНО-ВСПОМОГАТЕЛЬНОГО СОСТАВА ОБРАЗОВАТЕЛЬНЫХ УЧРЕЖДЕНИЙ В УСЛОВИЯХ МОДЕРНИЗАЦИИ ОБРАЗОВАНИЯ}

(C) 2016

А.М. Санько, кандидат педагогических наук, доцент кафедры теории и методики профессионального образования

Самарский национальный исследовательский университет имени академика С.П. Королёва, Самара (Россия)

Аннотация. В статье рассматривается изменение содержания профессиональной деятельности специалистов учебно-вспомогательного состава образовательных учреждений в условиях модернизации высшего образования и структурной ломки исторически сложившихся традиций организации деятельности по управлению различными процессами в вузе в ходе их объединения (на примере слияния двух университетов г. Самары вуза, осуществляющего подготовку в области классического естественнонаучного и гуманитарного образования, и вуза, осуществляющего подготовку специалистов для узкой высокотехнологичной, имеющей стратегически важное значение для обороноспособности государства отрасли). Описываются содержание и сущность социально-технологической деятельности специалистов учебно-вспомогательного состава образовательных учреждений и трудности, возникающие при перестройке с одного вида деятельности (коммуникация) на другой (работы с программными продуктами и сервисами). Рассматривается роль грамотного взаимодействия специалистов учебно-вспомогательного состава всех структурных подразделений для эффективной организации по управлению деятельностью всего вуза. Представлены результаты анализа деятельности специалистов 